Bull. Mater. Sci., Vol. 23, No. 4, August 2000, pp. 249-253. (C) Indian Academy of Sciences.

\title{
Optimization of time-temperature schedule for nitridation of silicon compact on the basis of silicon and nitrogen reaction kinetics
}

\author{
J RAKSHIT and P K DAS* \\ Central Glass and Ceramic Research Institute, Jadavpur, Calcutta 700 032, India
}

MS received 27 March 2000; revised 1 June 2000

\begin{abstract}
A time-temperature schedule for formation of silicon-nitride by direct nitridation of silicon compact was optimized by kinetic study of the reaction, $3 \mathrm{Si}+2 \mathrm{~N}_{2}=\mathrm{Si}_{3} \mathrm{~N}_{4}$ at four different temperatures $\left(1250^{\circ} \mathrm{C}\right.$, $1300^{\circ} \mathrm{C}, 1350^{\circ} \mathrm{C}$ and $1400^{\circ} \mathrm{C}$ ). From kinetic study, three different temperature schedules were selected each of duration $20 \mathrm{~h}$ in the temperature range $1250^{\circ}-1450^{\circ} \mathrm{C}$, for complete nitridation. Theoretically full nitridation (100\% i.e. 66.7\% weight gain) was not achieved in the product having no unreacted silicon in the matrix, because impurities in $\mathrm{Si}$ powder and loss of material during nitridation would result in 5-10\% reduction of weight gain.

Green compact of density $<66 \%$ was fully nitrided by any one of the three schedules. For compact of density $>66 \%$, the nitridation schedule was maneuvered for complete nitridation. Iron promotes nitridation reaction. Higher weight loss during nitridation of iron doped compact is the main cause of lower nitridation gain compared to undoped compact in the same firing schedule. Iron also enhances the amount of $\beta-\mathrm{Si}_{3} \mathrm{~N}_{4}$ phase by formation of low melting $\mathrm{FeSi}_{x}$ phase.
\end{abstract}

Keywords. Reaction sintered silicon nitride; nitridation; reaction kinetics.

\section{Introduction}

Formation of reaction sintered silicon-nitride products by direct nitridation of silicon powder compact has economical advantage compared to other forming processes for near net shape formation (Haggerty 1997). The only difficulty is the requirement of long time for complete nitridation. To overcome this difficulty, methods have been developed using high purity silane derived silicon powder (Gregory et al 1987; Sheldon and Haggerty 1989) which produced nitridation products in short time. They are costly and relatively tough for using sub-micron size Si powder in inert atmosphere. Previous work on reaction schedule for reaction bonding formation of silicon nitride showed a long-time nitridation reaction schedule under normal nitriding condition (Mangels 1977; Danforth and Richman 1983; Heinrich 1987; Barsoum et al 1989; Zhang 1996). Complete nitridation $(100 \%)$ of silicon via the reaction, $3 \mathrm{Si}+2 \mathrm{~N}_{2}=\mathrm{Si}_{3} \mathrm{~N}_{4}$, would occur by a theoretical weight gain of $66.7 \%$, but the practical weight gain (after an apparently complete reaction) was found to be much lower in presence of $\mathrm{O}_{2}$.

In the present work, a study on nitridation kinetics of silicon powder compacts of different green densities was performed in 1 atmosphere $\mathrm{N}_{2}$ at different temperatures. Based on the results of nitridation of the compacts, the

\footnotetext{
*Author for correspondence
}

process of nitridation was optimized following three different firing schedules as discussed in the next section to complete the nitridation in short time. The process was explained in terms of compactness of the powder, additive $(\mathrm{Fe})$ content and associated reaction kinetics.

\section{Experimental}

Commercial Si powder of $\sim 97.5 \%$ purity (after milling) was used as starting $\mathrm{Si}$ powder containing $\mathrm{Al}_{2} \mathrm{O}_{3}: 1 \cdot 22 \%$ (from alumina ball used for grinding), Fe: $0.41 \%$, Ti : $0.22 \%$, Ca: $0.53 \%,(\mathrm{Na}+\mathrm{K}): 0.1 \%$ by weight as major impurities. Si powder (Indian Metals and Ferroalloys, Bhubaneswar) was ball-milled to a mean particle diameter of $\sim 4.83 \mu \mathrm{m}$. Cylindrical pellets of $\sim 20 \mathrm{~mm}$ dia and 5$6 \mathrm{~mm}$ thickness were fabricated at $15 \mathrm{MPa}$ and $50 \mathrm{MPa}$ pressure. Iron powder ( $1 \%$ by weight and $98.2 \%$ purity) was thoroughly mixed with $\mathrm{Si}$ powder in acetone for $1 \mathrm{~h}$ and pellets of iron doped $\mathrm{Si}$ were made at $50 \mathrm{MPa}$ pressure. For kinetic study, nitridation of silicon compacts was performed at $1250^{\circ} \mathrm{C}, 1300^{\circ} \mathrm{C}, 1350^{\circ} \mathrm{C}$ and $1400^{\circ} \mathrm{C}$ in a controlled atmosphere vacuum tubular furnace. The rate of increase of temperature was kept same during the study and nitridation weight gain was determined for certain interval of time. From kinetic study, three different temperature schedules were selected as discussed in the next section. The extent of nitridation after firing in a particular schedule was determined by weight gain 
measurement. Percent weight gain was expressed as ' $\%$ nitrided' (66.7\% weight gain $=100 \%$ nitrided). Densities of both green and nitrided samples were determined from dimensions and water immersion technique, respectively. Quantitative estimation of phases were determined by quantitative X-ray analysis method outlined by Gazzara and Messier (1977). Microstructure of the interior surface of the polished samples was observed by incident light optical microscope (Ortholux II POL BK, Leitz, Germany).

\section{Results and discussion}

A linear relationship between the square of 'fraction nitrided' vs 'time' was observed by Biswas and Mukerji (1980) during the kinetic study of undoped Si powder in $\mathrm{N}_{2}$. The reaction kinetics of $\mathrm{Si}$ and $\mathrm{N}_{2}$ (Atkinson and Moulson 1976) doped with $1 \% \mathrm{Fe}, \mathrm{Ni}$ and $\mathrm{Cr}$ (at $1370^{\circ} \mathrm{C}$ ) showed increased formation of silicon nitride compared to undoped $\mathrm{Si}$. The same result was observed by Messier and Wong (1973) with $1 \%$ iron doped Si compact.

Weight gain (in terms of fraction nitrided) of $\mathrm{Si}$ and $\mathrm{N}_{2}$ reaction at different temperatures and pressures of green compaction is shown in figures $1 \mathrm{a}$ and $\mathrm{b}$ in which parabolic nitriding kinetics is observed as,

$$
\alpha^{n}=k t
$$

where $\alpha$ is fraction nitrided, $k$ is a constant and $t$, the reaction time. The value of $n$, however, changes with forming pressure of pellets i.e. compactness of the Si particles. In the present case $n \approx 2$ seems to fit well for pellets pressed at $15 \mathrm{MPa}$. But for the pellets pressed at $50 \mathrm{MPa}$, the value of ' $n$ ' lies between 2 and 3. Figure 2 shows the extent of nitridation (obtained from reaction kinetics) of green compacts pressed at $15 \mathrm{MPa}$ and $50 \mathrm{MPa}$ at different temperatures (viz. $1250^{\circ} \mathrm{C}, 1300^{\circ} \mathrm{C}, 1350^{\circ} \mathrm{C}$ and $1400^{\circ} \mathrm{C}$ ) for $10 \mathrm{~min}$ and $240 \mathrm{~min}$ duration. It is seen from figure 2 that 10 min nitriding at $1400^{\circ} \mathrm{C}$ would result in an additional $24 \%$ nitrided product compared to the same (pressed at $15 \mathrm{MPa}$ ) sample fired at $1250^{\circ} \mathrm{C}$. This increment is about $32 \%$ for sample pressed at $50 \mathrm{MPa}$. When nitriding reaction time is increased from $10 \mathrm{~min}$ to $240 \mathrm{~min}$ (figure 2), increment of nitridation for sample (pressed at $15 \mathrm{MPa}$ ) fired at $1250^{\circ}$ and $1300^{\circ} \mathrm{C}$ was about $11 \%$ and $16 \%$ respectively, whereas, such increment was about $21 \%$ and $23 \%$ for same sample fired at $1350^{\circ}$ and $1400^{\circ} \mathrm{C}$. Similar is the case for samples pressed at $50 \mathrm{MPa}$, in which more than $30 \%$ increment (nitridation gain) was observed from $10 \mathrm{~min}$ to $240 \mathrm{~min}$ reaction time. Therefore, firing temperature above $1350^{\circ} \mathrm{C}$ would always favour nitride formation in short duration of firing time instead of firing at lower temperature. Initial fast reaction of $\mathrm{Si}$ and $\mathrm{N}_{2}$ may result in quick rise of temperature near the melting point of $\mathrm{Si}\left(1410^{\circ} \mathrm{C}\right)$ with a result of unfavourable melting of $\mathrm{Si}$ before complete nitridation, because heat of reaction of Si nitridation is $-724 \mathrm{KJ} \mathrm{mol}^{-1}$ (JANAF 1971). Further nitrogen diffusion would be stopped due to closing of pores or channels by molten $\mathrm{Si}$. On considering the above fact, three different firing schedules were selected each of duration $20 \mathrm{~h}$ as below:

Schedule A: $\left(1250^{\circ}-1400^{\circ} \mathrm{C}\right) \times 2 \mathrm{~h}+1400^{\circ} \mathrm{C} \times 18 \mathrm{~h}$.

Schedule B: $1350^{\circ} \mathrm{C} \times 17 \mathrm{~h}+1400^{\circ} \mathrm{C} \times 3 \mathrm{~h}$.

Schedule C: $\left(1250^{\circ}-1400^{\circ} \mathrm{C}\right) \times 2 \mathrm{~h}+1400^{\circ} \mathrm{C} \times 14 \mathrm{~h}$ $+1450^{\circ} \mathrm{C} \times 4 \mathrm{~h}$.

In schedules $\mathrm{A}$ and $\mathrm{C}$, slow rise of temperature from $1250^{\circ} \mathrm{C}$ to $1400^{\circ} \mathrm{C}$ was maintained (about $1^{\circ} \mathrm{C} / \mathrm{min}$ rise from $1300^{\circ}-1400^{\circ} \mathrm{C}$ ) to avoid melting of $\mathrm{Si}$ and
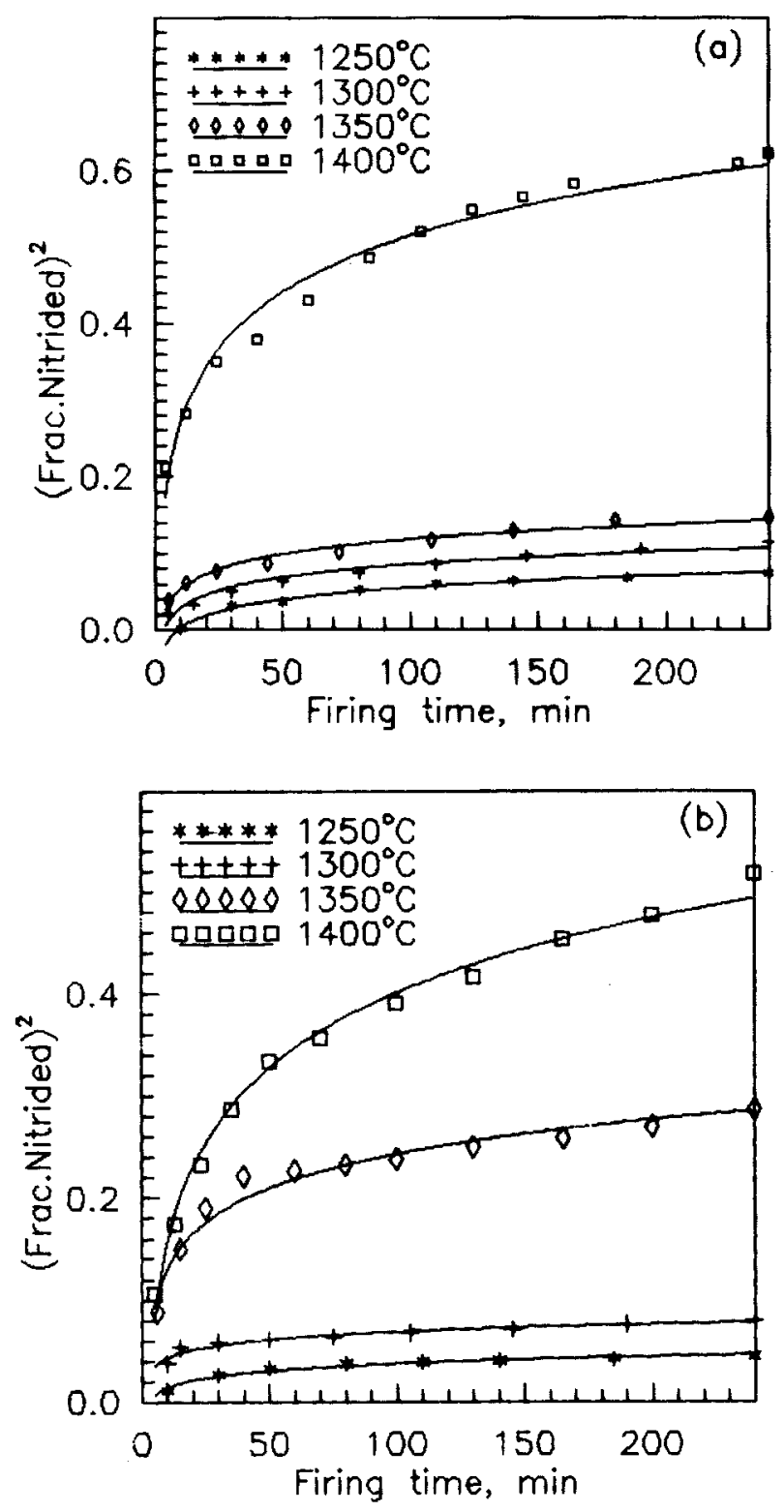

Figure 1. Nitriding kinetics of Si compact pressed at (a) $15 \mathrm{MPa}$ and (b) $50 \mathrm{MPa}$ at different temperatures. 
completed in $2 \mathrm{~h}$ duration. This precaution was taken in this study to avoid fast nitridation reaction with a result of quick rise of local temperature above the melting point of $\mathrm{Si}$. Schedule $\mathrm{C}$ differs from A as firing was done above the melting point of $\mathrm{Si}\left(\right.$ at $\left.1450^{\circ} \mathrm{C}\right)$ for $4 \mathrm{~h}$ duration to enhance nitridation.

Table 1 shows the results of nitridation in three schedules. Densities of green compact made by $15 \mathrm{MPa}$ pressure are lower $(<66 \%$ T.D.) compared to compact (>66.5\% T.D.) pressed at $50 \mathrm{MPa}$. For iron doped (1\%) samples, slightly higher $\%$ of relative green density was achieved compared to undoped compact. The \% relative density (\% T.D.) of nitrided products depend directly on

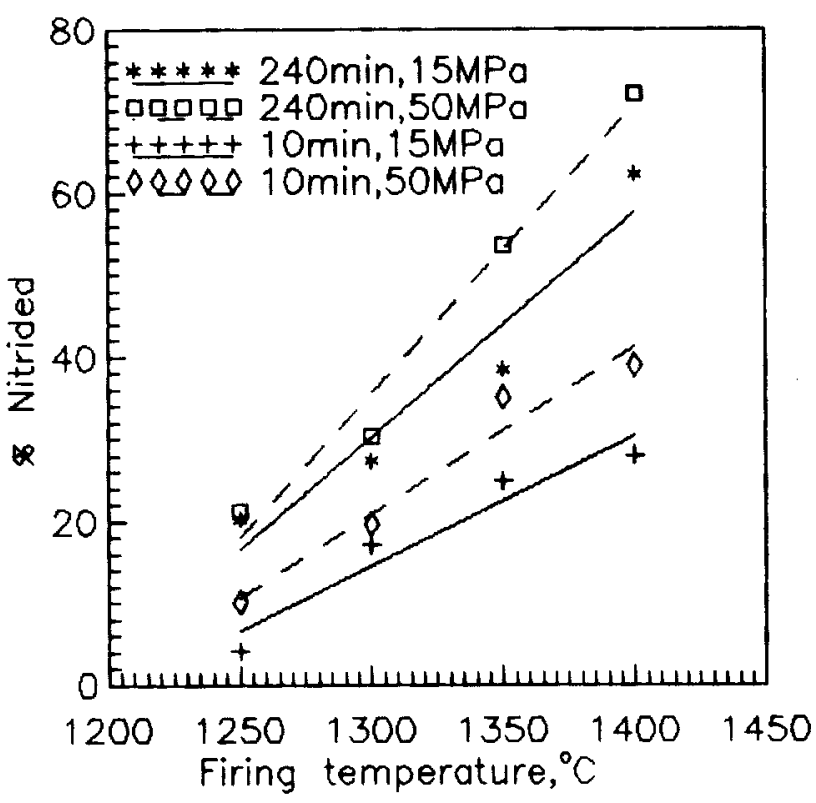

Figure 2. Extent of nitridation of green preform (pressed at 15 and $50 \mathrm{MPa}$ ) for $10 \mathrm{~min}$ and $240 \mathrm{~min}$ duration. both the green density as well as \% nitridation. Nitrided density is higher for samples (of similar nitridation) having higher green density (c.f. samples 2 and 3 in table 1). The higher amount of nitridation of nitrided samples (pressed at $15 \mathrm{MPa}$ ) compared to nitrided samples (pressed at $50 \mathrm{MPa}$ ) are responsible for the lower density (i.e. higher porosity) of the green preform, which facilitates the nitrogen diffusion into the interior of the compact as a result of more nitridation. From table 1 it is evident that, compact having low green relative density (<66\% T.D.) can be fully nitrided by any one of the three firing schedules. On the other hand, for specimens of high green density (>66.5\% T.D.) schedule B is not suitable for complete nitridation and results in poor nitridation $(<80 \%)$, which indicates the presence of unreacted $\mathrm{Si}$ in the products (samples 6 and 10 in table 1). Theoretically full nitridation $(100 \%$ i.e. $66.7 \%$ weight gain) products were not achieved in all the nitridation reactions where free silicon is nil or in negligible amount. The impurities in the $\mathrm{Si}$ powder (Riley 1977) and loss of materials during nitridation (Boyer et al 1977; Mitomo 1977) are the main causes of apparent low '\% nitrided' values.

A linear and almost linear (except for samples pressed at $15 \mathrm{MPa}$ ) relationship between '\% nitrided' vs '\% T.D.' was observed for $\mathrm{Fe}$-doped and undoped nitrided samples respectively (figure 3 ). The $\%$ T.D. of fully nitrided products depend on their green compact density as well as \% nitridation as stated earlier. The wide variation of green density $(64.8-65.7 \%)$ and \% nitridation $(89.6-92.2 \%)$ of sample pressed at $15 \mathrm{MPa}$ results in a non linear relationship as shown in figure 3. Scattered low values of relative densities are observed for samples (pressed at $50 \mathrm{MPa}$ ) having considerable amount of unreacted $\mathrm{Si}$ (samples 6 and 10). Relatively high nitrided densities (80-81\%) of Fe-doped samples-like (sample pressed at $15 \mathrm{MPa}$ $(80 \cdot 2 \%)$ ) reveal that Fe-doping is favourable for complete nitridation in dense green compact.

Table 1. Characteristics of nitrided samples.

\begin{tabular}{|c|c|c|c|c|c|c|c|c|}
\hline \multirow{2}{*}{$\begin{array}{l}\text { Sample } \\
\text { no. }\end{array}$} & \multirow{2}{*}{$\begin{array}{c}\text { Firing } \\
\text { schedule }\end{array}$} & \multicolumn{2}{|c|}{$\%$ Relative density } & \multirow[b]{2}{*}{$\%$ Nitrided } & \multirow{2}{*}{$\begin{array}{c}\text { Unreacted } \\
\mathrm{Si}\end{array}$} & \multicolumn{3}{|c|}{ Phases present (\%) } \\
\hline & & Green & Nitrided & & & $\alpha-\mathrm{Si}_{3} \mathrm{~N}_{4}$ & $\beta-\mathrm{Si}_{3} \mathrm{~N}_{4}$ & $\mathrm{Si}_{2} \mathrm{~N}_{2} \mathrm{O}$ \\
\hline 1 & A & $65 \cdot 6$ & $80 \cdot 2$ & $92 \cdot 2$ & trace & $44 \cdot 0$ & $37 \cdot 5$ & $18 \cdot 5$ \\
\hline 2 & B & $65 \cdot 5$ & $79 \cdot 1$ & $89 \cdot 7$ & do & $76 \cdot 0$ & $24 \cdot 0$ & trace \\
\hline 3 & $\mathrm{C}$ & $65 \cdot 7$ & $80 \cdot 0$ & $89 \cdot 75$ & do & $62 \cdot 6$ & $32 \cdot 3$ & $5 \cdot 1$ \\
\hline 4 & A & $64 \cdot 8$ & $77 \cdot 6$ & $89 \cdot 6$ & do & $67 \cdot 0$ & $23 \cdot 1$ & $7 \cdot 9$ \\
\hline 5 & A & $67 \cdot 3$ & $78 \cdot 75$ & $88 \cdot 9$ & $0 \cdot 6$ & $79 \cdot 5$ & $19 \cdot 9$ & trace \\
\hline 6 & B & $66 \cdot 9$ & $73 \cdot 35$ & $70 \cdot 8$ & $5 \cdot 1$ & $70 \cdot 1$ & $24 \cdot 8$ & do \\
\hline 7 & $\mathrm{C}$ & $67 \cdot 2$ & $78 \cdot 7$ & $83 \cdot 75$ & $1 \cdot 5$ & $57 \cdot 8$ & $29 \cdot 7$ & $11 \cdot 0$ \\
\hline 8 & A & $67 \cdot 6$ & $78 \cdot 45$ & 81.75 & 0.6 & $57 \cdot 6$ & $38 \cdot 3$ & $3 \cdot 5$ \\
\hline 9 & A & $68 \cdot 2$ & $80 \cdot 8$ & 82.65 & 0.5 & $60 \cdot 7$ & $26 \cdot 8$ & $12 \cdot 0$ \\
\hline 10 & B & 67.9 & $76 \cdot 3$ & $77 \cdot 5$ & $3 \cdot 6$ & $47 \cdot 2$ & $36 \cdot 9$ & $12 \cdot 3$ \\
\hline 11 & $\mathrm{C}$ & $68 \cdot 1$ & $80 \cdot 65$ & 82.4 & trace & $57 \cdot 0$ & $43 \cdot 0$ & trace \\
\hline 12 & A & $67 \cdot 1$ & $80 \cdot 15$ & $81 \cdot 5$ & do & $75 \cdot 0$ & 18.9 & $6 \cdot 1$ \\
\hline
\end{tabular}

Sample nos 1-4 (pressed at 15 MPa), 5-8 (pressed at $50 \mathrm{MPa}$ ) and 9-12 (Fe-doped and pressed at $50 \mathrm{MPa})$. 


\subsection{Effect of iron}

Iron-doped samples (9-12) may be compared with similar undoped samples (5-8), as both were made at same pressure (50 MPa). Apparently iron addition do not affect nitridation weight gain ('\% nitrided' is low compared to undoped samples), but better nitridation would result in a particular firing schedule when followed by both doped and undoped specimens. Low nitridation gain may be accounted for by the loss of material during nitridation. Weight loss at the nitridation stage was measured by Boyer et al (1977) which indicated that $\mathrm{SiO}$ formed (in the presence of iron) via the reaction $\mathrm{Si}+\mathrm{SiO}_{2} \rightarrow 2 \mathrm{SiO}$, does not react within the compact. So the vapour phase reactions involving $\mathrm{SiO}$ play no significant part in the reaction system and supposed to be condensed as $\alpha-\mathrm{Si}_{3} \mathrm{~N}_{4}$ elsewhere in the reaction system. Iron induced devitrification of silica layer resulted in active oxidation of silicon at high temperature to generate $\mathrm{SiO}$, which further react with $\mathrm{N}_{2}$ gas to form $\alpha-\mathrm{Si}_{3} \mathrm{~N}_{4}$ and/or oxynitride (Barsoum et al 1989). The unreacted $\mathrm{Si}$ is found in higher amount in nitrided samples of undoped compact rather than in $\mathrm{Fe}$ doped compact (c.f. samples 6 and 10, 5 and 12 in table 1). The high '\% relative density' (nitrided) also supports the possibility of complete nitridation reaction (figure 3). Most significant effect of Fe doping was observed by addition of $50 \mathrm{ppm}$ to $1 \mathrm{w} / \mathrm{o} \mathrm{Fe}$ to $\mathrm{Si}$ powder (Atkison and Moulson 1976). Acceleration of nitridation by Fe may be due to (i) disruption and/or removal of silica layer on the Si particles (Atkinson and Moulson 1976) and (ii) formation of a low melting $\left(1208^{\circ} \mathrm{C}\right) \mathrm{FeSi}_{x}$ alloy, since it has been shown that $\mathrm{Fe}$-induced enhanced nitridation ceases

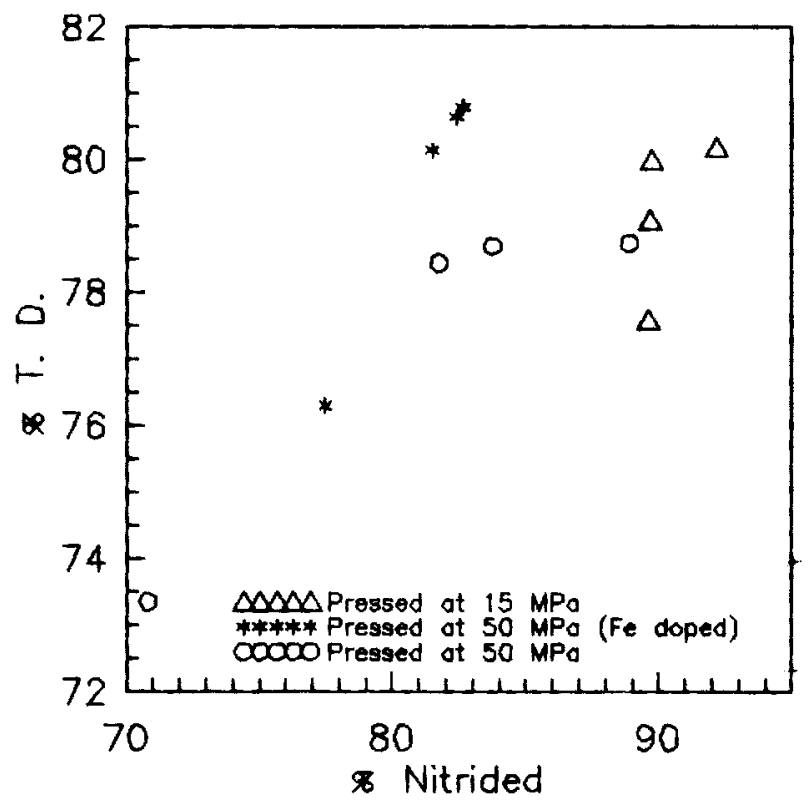

Figure 3. Relationship between '\% nitrided' vs '\% T.D.' of undoped and Fe-doped RBSN specimens. below $1200^{\circ} \mathrm{C}$, the $\mathrm{Fe}-\mathrm{Si}$ solidus temperature (Jayatilaka and Leake 1977). After removal of the oxide film, iron nucleates extra nitride growth at $\mathrm{Fe}-\mathrm{Si}$ melt sites (Boyer et al 1977). Zhang and Marino (1995) obtained $~ 6 \%$ excess nitrided product $\left(1350^{\circ} \mathrm{C}, 20 \mathrm{~h}\right)$ using $1 \mathrm{vol} \%$ $\mathrm{Ni}_{3} \mathrm{Al}$ in $\mathrm{Si}$ and suggested the accelerating effect of $\mathrm{Ni}_{3} \mathrm{Al}$ is to form a low melting liquid phase of silicious intermetallics.

Optical microscopic observations of finely ground interior surface of the RBSN specimens (both undoped and Fe-doped, fired in the same schedule C) reveal that the matrix is composed of light grey silicon nitride grains with pores (black) distributed throughout the matrix. Unreacted Si particles (bright in the photograph) are found to scatter. Unreacted $\mathrm{Si}$ is almost negligible in $\mathrm{Si}_{3} \mathrm{~N}_{4}$ matrix of Fe-doped sample (figure 5) compared to undoped sample (figure 4). The matrix of undoped $\mathrm{Si}_{3} \mathrm{~N}_{4}$ is more

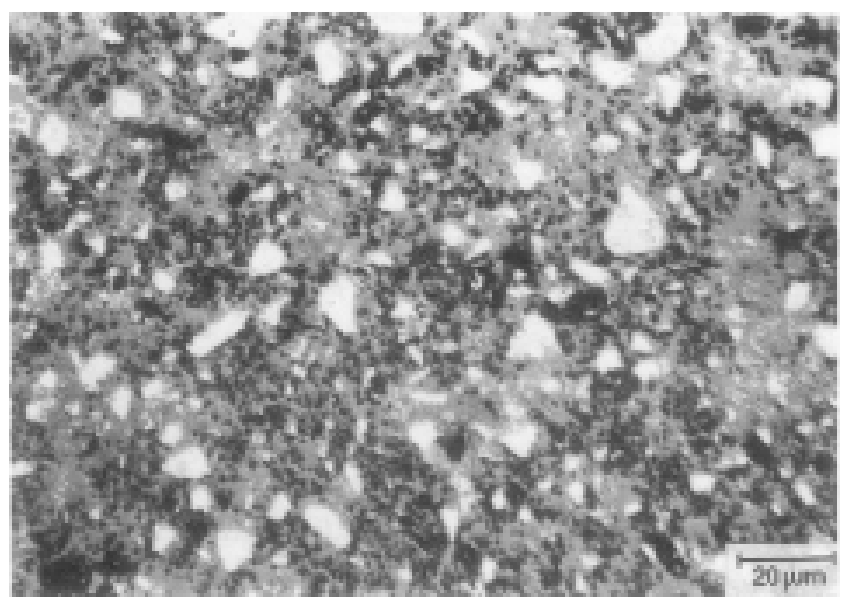

Figure 4. Optical photomicrograph of undoped (pressed at $50 \mathrm{MPa}$ ) nitrided (schedule C) sample, showing unreacted $\mathrm{Si}$ (bright) and finely distributed pores (black) in the matrix.

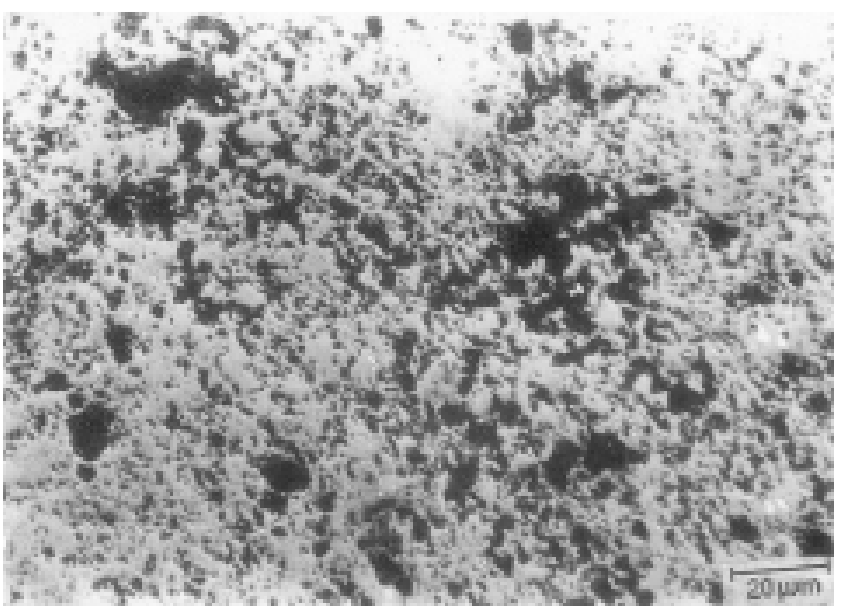

Figure 5. Optical photomicrograph of Fe-doped (pressed at $50 \mathrm{MPa}$ ) nitrided (schedule C) sample, showing absence of unreacted Si but some large pores (black) in the matrix. 
homogeneous (with finely distributed pores) compared to Fe-doped matrix in which some large pores are found to scatter and are possibly formed by $\mathrm{FeSi}_{\mathrm{x}}$ melt (Zhang and Marino 1995; Zhang 1996).

Another effect of iron is to increase the amount of $\beta$ $\mathrm{Si}_{3} \mathrm{~N}_{4}$ phase in silicon nitride matrix. Amount of $\beta$-Si ${ }_{3} \mathrm{~N}_{4}$ is higher in Fe-doped sample compared to undoped sample when prepared by same firing schedule (c.f. samples 5 and 9, 6 and 10, 7 and 11 in table 1). According to Longland and Moulson (1978), vapour phase reaction between $\mathrm{Si}$ and $\mathrm{N}_{2}$ bearing species lead only to $\alpha-\mathrm{Si}_{3} \mathrm{~N}_{4}$ or amorphous silicon nitride, the direct reaction between solid $\mathrm{Si}$ and $\mathrm{N}_{2}$ as well as reaction involving a suitable liquid phase lead to $\beta-\mathrm{Si}_{3} \mathrm{~N}_{4} . \beta-\mathrm{Si}_{3} \mathrm{~N}_{4}$ precipitates within $\mathrm{FeSi}_{x}$ liquid and the rate of growth is determined by the solubility and diffusivity of $\mathrm{N}_{2}$ in $\mathrm{FeSi}_{x}(\mathrm{l})$. Such $\beta$-growth is directly proportional to the amount of liquid, i.e. iron content (Boyer and Moulson 1978). The same workers were able to link $\beta-\mathrm{Si}_{3} \mathrm{~N}_{4}$ growth with the presence of an $\mathrm{FeSi}_{x}$ phase by nitriding compact of high purity $\mathrm{Si}$ with Fe-doped. According to Messier and Riley (1977), growth of $\beta-\mathrm{Si}_{3} \mathrm{~N}_{4}$ from a liquid phase is a process identical to the phase transformation of $\alpha$ - to $\beta-\mathrm{Si}_{3} \mathrm{~N}_{4}$ from the liquid after the solution of $\alpha-\mathrm{Si}_{3} \mathrm{~N}_{4}$ in the silicate melt during hot pressing.

\section{Conclusions}

(I) Nitridation kinetics of compacted Si bears a relation of $\alpha^{n}=k t$ ( $\alpha$-fraction nitrided in time $t, k$ being constant), where $n \geq 2$ when compacted at pressure more than $15 \mathrm{MPa}$.

(II) Kinetic study of silicon nitrogen reaction reveals that initial nitridation is quite rapid at $1250^{\circ} \mathrm{C}$ but firing temperature must be raised above $1350^{\circ} \mathrm{C}$ after few hours $(\sim 2 \mathrm{~h})$ in order to increase nitridation rate and hence to reduce firing time.

(III) The extent of nitridation depend on the green density of the compact. Full nitrided products are obtained in fixed time ( $20 \mathrm{~h}$ in the present case) for green compact of low relative density ( $<66 \%$ T.D.). The same observations are found for compact of high green density $(>66.5 \%$
T.D.), when nitridation is carried out for long time $(\sim 18 \mathrm{~h})$ at higher temperature $\left(1400^{\circ} \mathrm{C}-1450^{\circ} \mathrm{C}\right)$.

(IV) Iron (1 w/o of $\mathrm{Si})$ promotes nitridation reaction and enhances the amount of $\beta-\mathrm{Si}_{3} \mathrm{~N}_{4}$ phase.

\section{Acknowledgement}

The help rendered by the staff of CGCRI, Calcutta, is gratefully acknowledged.

\section{References}

Atkinson A and Moulson A J 1976 Sci. Ceram. 8111

Barsoum M, Kanjutar P and Koczak M J 1989 Ceram. Eng. Sci. Proc. 10794

Biswas S K and Mukerji J 1980 J. Am. Ceram. Soc. 63232

Boyer S M and Moulson A J 1978 J. Mater. Sci. 131637

Boyer S M, Sang D and Moulson A J 1977 Nitrogen ceramics (ed.) F L Riley (Leyden: Noordhoff ) p. 297

Danfort S C and Richman M H 1983 Am. Ceram. Soc. Bull. 57 501

Gazzara P Charles and Messier Donald R 1977 Ceram. Bull. 56297

Gregory J Otto, Lee Sang Back and Flagan C Richard $1987 \mathrm{~J}$. Am. Ceram. Soc. 70 C-52

Haggerty J S 1997 Silicon based structural ceramics (eds) B W Sheldon and S C Danfort (USA: American Ceram. Soc.) $\mathbf{4 2}$ p. 29

Heinrich J 1987 Adv. Ceram. Mater. 2239

JANAF 1971 Thermomechanical tables, 2nd Ed., NBS

Jayatilaka A de S and Leake J A 1977 Nitrogen ceramics (ed.) F L Riley (Leyden: Noordhoff ) p. 289

Longland P and Moulson A J 1978 J. Mater. Sci. 132279

Mangels J A 1977 Nitrogen ceramics (ed.) F L Riley (Leyden: Noordhoff ) p. 569

Messier D R and Wong P 1973 J. Am. Ceram. Soc. 56480

Messier D R and Riley F L 1977 Nitrogen ceramics (ed.) F L Riley (Leyden: Noordhoff ) p. 141

Mitomo M 1977 J. Mater. Sci. 12273

Riley F L 1977 Nitrogen ceramics (ed.) F L Riley (Leyden: Noordhoff ) p. 265

Sheldon B W and Haggerty J S 1989 Ceram. Eng. Sci. Proc. 10 784

Zhang B R 1996 J. Am. Ceram. Soc. 80269

Zhang B R and Marino F 1995 J. Euro. Ceram. Soc. 151065 